\title{
Effect of extruded grain feed, with the preliminary germination of rapeseed, on the cicatricial digestion of dairy cows and calves
}

\author{
Vladimir Sofronov, Ramil Fayzrakhmanov, Elvir Yamaev, Nadezhda Danilova*, Elena Kuznetsova, and Pavel Sofronov \\ Kazan State Academy of Veterinary Medicine named after N.E. Bauman, Kazan 420029, Republic of Tatarstan, Russia
}

\begin{abstract}
This article describes the scientific and production experience conducted in the Druzhba LLC, of the Buinsky district of the Republic of Tatarstan. The purpose of the scientific and production experiment is to study the effect of extruded feed, with the preliminary germination of rapeseed in a $0.05 \%$ nicotinic acid solution, on the cicatricial digestion of calves and dairy cows. During the experiment, it is found that feeding calves and dairy cows with extruded feed with preliminary germination of rapeseed in a $0.05 \%$ nicotinic acid solution had a positive effect on cicatricial digestion, contributing to an increase in ammonia to 8.7 and $7.9 \%$, acetic acid $-12,6$ and $11.5 \%$ and propionic -13.4 and $12.6 \%$ acids, with a decrease in butyric acid -12.8 and $10.4 \%$, an increase in the total microbial number -84.0 and $16.3 \%$, in including cellulolytic bacteria - 11.6 and $14.3 \%$, ciliates -13.4 and $12.9 \%$, as well as the enzymatic activity of cicatricial microflora, respectively accordingly, in comparison with the control and the group where the grain feed is subjected to only one extrusion. Thus, the use of extruded feed with pre-germinated rapeseed in feeding calves and dairy cows improved the underlying indices of cicatricial digestion compared with the control group of animals fed with non-extruded feed and the group of animals fed with extruded feed.
\end{abstract}

\section{Introduction}

A feature of ruminants is cicatricial digestion and anaerobic microflora found in cicatricial contents [1-5]. In contrast to animals with a single-chamber stomach, during cicatricial digestion, the breakdown of nutrients occurs both due to enzymes of the feed itself and to enzymes produced by the microflora of cicatricial contents [6, 7]. The vital activity of cicatricial microorganisms depends on many factors, such as stress, nutritional value of the diet, quality of feeds, introduction of feed additives into the diet, the level of easily digestible carbohydrates, since fiber hydrolysis decreases as with a high level of easily digestible carbohydrates (microorganisms use only efficiently digestible carbohydrates), and with a low level of easily digestible carbohydrates (the number of microflora decreases) [8]. Monosaccharides received in cicatricial digestion up to 35-45\% turn into volatile fatty acids (acetic, propionic, butyric acids), which cover ruminant energy requirements by about $40 \%$ [9].

Failure to comply with the technology of preparation and storage of feed leads to the fact that the feed used is of poor quality. This situation is not uncommon for many reasons. Therefore, the preparation of feeds that helps optimize cicatricial digestion be of great importance for animal husbandry. Thanks to the preparation, it is possible to use such feeds that are used slightly, due to the content of anti-nutritional factors. Rapeseed refers to such crops.
The above circumstances led to the statement of the purpose of this study. The purpose of the study is to study the effect of extruded feed with the preliminary germination of rapeseed in a $0.05 \%$ nicotinic acid solution on the cicatricial digestion of calves and dairy cows.

\section{Materials and methods}

A production experiment was carried out under the conditions of LLC "Druzhba" of the Buinsky district of the Tatarstan Republic. The experiment is aimed at studying the effect of extruded feed with germinated rapeseed on the body of young cattle from two to eight months of age and dairy cows. Animals were divided into three groups: calves of 20 animals in each group, and cows of 10 animals in each group. The experimental and control groups of the calves formed based on analogs, taking into account the live weight and age; the experimental and control groups of the cows are formed based on age, lactation and milk yield according to the following scheme:

- Group 1 (control) - MR (main household ration) with the addition of $0.4 \mathrm{~kg}$ of extruded feed (from 0.3 to $0.5 \mathrm{~kg}$ depending on age) in calves and $1.5 \mathrm{~kg}$ for dairy cows. The composition of the extruded feed included the following components: rye $-25 \%$, peas $-42 \%$, barley $-18 \%$, corn $-15 \%$;

- Group 2 (experience) - MR, with the addition of 0.4 $\mathrm{kg}$ of extruded feed (from 0.3 to $0.5 \mathrm{~kg}$ depending on age)

Corresponding author: danai58@yandex.ru 
in calves and $1.5 \mathrm{~kg}$ for dairy cows. The composition of the extruded feed included the following components: rye $25 \%$, rapeseed $30 \%$, peas $-20 \%$ and corn $25 \%$;

- Group 3 (experiment) - MR, with the addition of $0.4 \mathrm{~kg}$ of extruded feed (from 0.3 to $0.5 \mathrm{~kg}$ depending on age) in calves and $1.5 \mathrm{~kg}$ for dairy cows. The composition of the extruded feed included the following components: rye $-25 \%$, rapeseed $-30 \%$, peas $-20 \%$ and corn $-25 \%$, with the preliminary germination of rapeseed before extrusion.

Germination of rapeseed is carried out in containers with a $0.05 \%$ nicotinic acid solution, grain thickness of up to $1 \mathrm{~cm}$, time spent on germination of grain 2-3 days when rapeseed sprouts reached 1.5-2 $\mathrm{mm}$, and the grain mass was periodically mixed. The ambient temperature in the room was at the level of $180-200{ }^{\circ} \mathrm{C}$. The use of nicotinic acid is justified by its resistance to high temperature (since it is melting point is $235-236{ }^{\circ} \mathrm{C}$ ) to light and oxidation, as well as the fact that it has an anti-toxic property, which is confirmed by existing research data [10].

During the experiment, the microclimate of the room where the animals were kept met the hygiene requirements and feeding corresponded to generally accepted standards. The nutritional excitability of experimental animals was within the physiological norm.

To study the metabolic rate of the experimental animals' organisms, and the influence of the test food, the original cicatricial content in animals is studied at the beginning and end of the experiment. Samples of cicatricial content were taken using a food probe 1 hour before morning feeding. Samples of cicatricial content were determined: 1 - acidity $(\mathrm{pH})$ on a $\mathrm{pH}$ meter, $2-$ ammonia content - using the Kjeldahl method, 3 number of microorganisms and ciliates, by the calculation method in the Goryaev chamber, 4 concentration of volatile fatty acids - in a Markham apparatus with subsequent distillation on a gas chromatograph, 5 - functional activity of the rumen microflora using a sample with methylene blue, 6 amylolytic (using a photoelectric colorimeter) and cellulolytic activity (using a cotton thread) - in vitro [11].

\section{Results}

The experiment is conducted on calves from two to eight months of age for six months. At the beginning and end of the experiment, the state of cicatricial digestion in experimental animals is assessed. The results of the study of cicatricial digestion are presented in Table 1.

The reaction of the environment of the rumen during digestion is an important indicator that determines the state of fermentation processes, the formation of metabolites, absorption, and use of them in the body.

The analysis of this data shows that at the beginning and the end of the study, the acidity of the cicatricial content is slightly alkaline or neutral. These circumstances indicate healthy digestion in the rumen of experimental animals.

Table 1. The results of the study of cicatricial content (experimental calves)

\begin{tabular}{|c|c|c|c|c|}
\hline \multirow{2}{*}{\multicolumn{2}{|c|}{ Indicator }} & \multicolumn{3}{|c|}{ Group } \\
\hline & & 1 & 2 & 3 \\
\hline & & \multicolumn{3}{|c|}{ Background } \\
\hline & Acidity, $\mathrm{pH}$ & $6.58 \pm 0.31$ & $6.57 \pm 0.32$ & $6.58 \pm 0.34$ \\
\hline & Ammonia, mg / 1 & $123 \pm 6.1$ & $121 \pm 6.0$ & $124 \pm 6.7$ \\
\hline \multirow{3}{*}{$\begin{array}{l}\text { Volatile fatty } \\
\text { acid, mol / } 1\end{array}$} & Acetic acid & $45.9 \pm 2.1$ & $45.4 \pm 2.3$ & $45.7 \pm 2.7$ \\
\hline & Propionic acid & $11.2 \pm 0.8$ & $11.6 \pm 0.7$ & $11.5 \pm 0.9$ \\
\hline & Butyric acid & $9.1 \pm 0.4$ & $8.9 \pm 0.4$ & $9.0 \pm 0.5$ \\
\hline \multicolumn{2}{|c|}{ Total microbial count, $\mathrm{CFU} / \mathrm{ml}$} & $6.34 \times 10^{8} \pm 0.32$ & $6.27 \times 10^{8} \pm 0.31$ & $6.31 \times 10^{8} \pm 0.30$ \\
\hline \multicolumn{2}{|c|}{ Cellulolytic bacteria, $\mathrm{CFU} / \mathrm{ml}$} & $5.13 \times 10^{6} \pm 0.27$ & $5.09 \times 10^{6} \pm 0.31$ & $5.18 \times 10^{6} \pm 0.34$ \\
\hline \multicolumn{2}{|c|}{ The number of ciliates, thousand / ml } & $398.8 \pm 19.2$ & $408.2 \pm 21.4$ & $410.8 \pm 21.7$ \\
\hline \multicolumn{2}{|c|}{ Movement of ciliates, score } & $3.5 \pm 0.1$ & $3.6 \pm 0.1$ & $3.4 \pm 0.1$ \\
\hline \multicolumn{2}{|c|}{ The activity of cicatricial microflora, min. } & $4.4 \pm 0.1$ & $4.3 \pm 0.1$ & $4.3 \pm 0.1$ \\
\hline \multirow[t]{2}{*}{ Activity } & Amylolytic activity. $\mathrm{mg} / \mathrm{ml}$ & $27.8 \pm 1.0$ & $27.7 \pm 1.1$ & $27.9 \pm 1.0$ \\
\hline & Cellulolytic activity. $\%$ & $6.0 \pm 0.3$ & $5.9 \pm 0.3$ & $5.8 \pm 0.4$ \\
\hline & & \multicolumn{3}{|c|}{ After 6 months of experiment } \\
\hline & Acidity, $\mathrm{pH}$ & $6.72 \pm 0.32$ & $6.81 \pm 0.34$ & $6.89 \pm 0.35$ \\
\hline & Ammonia, mg / 1 & $119.8 \pm 6.0$ & $124.9 \pm 6.7$ & $130.2 \pm 7.1$ \\
\hline \multirow{3}{*}{$\begin{array}{l}\text { Volatile fatty } \\
\text { acid, mol / } 1\end{array}$} & Acetic acid & $58.5 \pm 2.9$ & $63.8 \pm 3.4$ & $65.9 \pm 3.5$ \\
\hline & Propionic acid & $11.9 \pm 0.6$ & $13.0 \pm 0.7$ & $13.5 \pm 0.9$ \\
\hline & Butyric acid & $10.2 \pm 0.5$ & $9.1 \pm 0.4$ & $8.9 \pm 0.4$ \\
\hline \multicolumn{2}{|c|}{ The number of ciliates, thousand / $\mathrm{ml}$} & $6.81 \times 10^{8} \pm 0.34$ & $7.14 \times 10^{8} \pm 0.32$ & $7.38 \times 10^{8} \pm 0.35$ \\
\hline \multicolumn{2}{|c|}{ Total microbial count, CFU / ml } & $5.68 \times 10^{6} \pm 0.29$ & $6.15 \times 10^{6} \pm 0.30$ & $6.34 \times 10^{6} \pm 0.35$ \\
\hline \multicolumn{2}{|c|}{ Cellulolytic bacteria, CFU / ml } & $567.4 \pm 28.1$ & $613.5 \pm 30.8$ & $643.5 \pm 34.8^{*}$ \\
\hline \multicolumn{2}{|c|}{ Movement of ciliates, score } & $3.9 \pm 0.1$ & $4.3 \pm 0.1$ & $5.0 \pm 0.1$ \\
\hline \multicolumn{2}{|c|}{ The activity of cicatricial microflora, min. } & $4.4 \pm 0.1$ & $4.5 \pm 0.1$ & $4.6 \pm 0.1$ \\
\hline \multirow[t]{2}{*}{ Activity } & Amylolytic activity. mg / ml & $35.5 \pm 1.3$ & $36.4 \pm 1.4$ & $37.8 \pm 1.5$ \\
\hline & Cellulolytic activity. $\%$ & $5.4 \pm 0.2$ & $7.2 \pm 0.4$ & $7.9 \pm 0.4$ \\
\hline
\end{tabular}

$* \mathrm{P} \leq 0.05$ 
Full feeding of animals is associated both with a stable reaction of the environment of the contents of the rumen and with the use of non-protein nitrogen, presented in the form of ammonia [12, 13].

The experiment showed that the data of the third experimental group show an increase in ammonia compared with the control (by $8.7 \%$ ) and the second experimental group (4.2\%). It can be assumed that this increase in ammonia content is associated with increased protein breakdown due to its better availability due to extrusion of feed with its preliminary germination and indicates an increase in the rate of protein synthesis by microorganisms of cicatricial content.

Mono- and disaccharides enter the rumen with food or formed as a result of the breakdown of microorganisms in the rumen. In cicatricial content, mono- and disaccharides fermented to volatile fatty acids. Acetic acid serves as a source of energy and is a precursor of milk fat. Propionic acid is formed by the body as the primary precursor of glucose (gluconeogenesis in the liver) and is used in the synthesis of fats, stimulating the weight gain of the animal.

The content of volatile fatty acids is higher in the third experimental group, where the extrusion of grain with its preliminary germination is used to prepare the feed. So the amount of acetic acid in the third group is $12.6 \%$ higher compared to the control group, and $3.3 \%$ compared to the second (extrusion) experimental group. The data on the content of propionic acid are similar $13.4 \%$ more compared to the first group and $3.8 \%$ compared to the second group.

The amount of butyric acid, on the contrary, decreased by $12.8 \%$ compared with the first group and $2.2 \%$ compared with the second. Probably, the data presented are associated with an increase in di- and monosaccharides in calf feed, which was first germinated and then extruded.

The grains used in the feed for calves of the third group were first germinated and then extruded. This technology led to an increase in pure and easily digestible nutrients in the feed of the third experimental group. This technology contributed to the partial breakdown of crude fiber to dextrins and simple sugars, and proteins to amino acids, which is revealed in preliminary experiments [14].

The technology for preparing feed for the third group contributed to an increase in the number of microorganisms in the cicatricial content. So, the total microbial number in the third experimental group compared with the control (first group) increased by $8.4 \%$, and cellulolytic bacteria - by $11.6 \%$.

Compared with the second group, where only one extrusion of feed is carried out, in the third group, the total microbial number is $3.4 \%$ more and cellulolytic bacteria $-3.1 \%$.

A similar picture is observed in the study of ciliates that promote mixing and loosening of the contents of the rumen, the synthesis of glycogen and complete animal protein, and partial breakdown of fiber and vegetable proteins. So the number of ciliates in the third group increased by $13.4 \%$ compared with the control group and by $4.9 \%$ compared with the second group.

An increase in amylolytic and cellulolytic activity of cicatricial microflora also indicates an improvement in the enzymatic activity of microflora of cicatricial content in the third experimental group compared with the control group by 2.3 and $1.5 \%$ and compared with the second experimental group by 1.5 and $0,7 \%$

Thus, the use of extruded feed with pre-germinated rapeseed in the feeding of calves of the third experimental group contributed to the improvement of the leading indicators of cicatricial digestion. So the amount of ammonia in the third experimental group increased by $8.7 \%$ compared with the control group, and the second experimental group (only one extrusion) $4.2 \%$, acetic acid $-12.6 \%$ and $3.3 \%$, propionic acids $13.4 \%$ and $3.8 \%$ of the total microbial number $-8.4 \%$, and cellulolytic bacteria - $11.6 \%$, and compared with the second group by 3.4 and $3.1 \%$, an increase in the number of ciliates by $13.4 \%$ and $4.9 \%$, respectively, as well as improving the enzymatic activity of microflora.

The next stage of production experience is the study of the effect of feed on dairy cows. The experimental design is similar to an experiment conducted on calves. At the beginning and end of the experiment, the estate of cicatricial digestion in experimental animals is studied. The results of the study are in Table 2 .

Analysis of the data shows that at the beginning and the end of the study, the acidity of the rumen content of dairy cows is slightly alkaline or neutral.

The data in the table indicate an increase in ammonia in the third experimental group (extrusion with preliminary germination) compared with the first control group by $7.9 \%$ and the second experimental group (extrusion) $-3.3 \%$.

The number of volatile fatty acids in the third experimental group was higher compared to the control: acetic acid $-11.5 \%$ and propionic acid $-12.6 \%$, and compared with the second experimental group -4.0 and $3.0 \%$, and the number butyric acid, by contrast, decreased by 10.4 and $3.0 \%$.

In the third experimental group, the total microbial number increased by $16.3 \%$ compared with the control group (first group), and cellulolytic bacteria $-14.3 \%$, and compared with the second experimental group -5.4 and $4.8 \%$

The number of ciliates in the third group increased by $12.9 \%$ compared with the control (first group) and by $5.1 \%$ in the second group.

The increase in the microflora in the cicatricial content is also confirmed by an increase in amylolytic and cellulolytic activity in the third experimental group compared to the control and the second experimental group.

Thus, the use of extruded feed with pre-germinated rapeseed in the feeding of dairy cows of the third experimental group contributed to an improvement in the underlying indices of cicatricial digestion compared with the first control group and the second experimental group, where only one extrusion of food was performed. So the amount of ammonia in the third experimental group increased by $7.9 \%$ compared with the control, and 
the second experimental group (only one extrusion) $3.3 \%$, acetic acid -11.5 and $4.0 \%$ and propionic -12.6 and $3.0 \%$, of the total microbial number -16.3 and $5.4 \%$, including cellulolytic bacteria increased by 14.3 and $4.8 \%$, an increase in the number of ciliates - 12.9 and $5.1 \%$, as well as improving the enzymatic activity of microflora of cicatricial content.

Table 2. Study of cicatricial content (dairy cows).

\begin{tabular}{|c|c|c|c|c|}
\hline \multirow{2}{*}{\multicolumn{2}{|c|}{ Indicator }} & \multicolumn{3}{|c|}{ Group } \\
\hline & & 1 & 2 & 3 \\
\hline & & \multicolumn{3}{|c|}{ Background } \\
\hline & Acidity, $\mathrm{pH}$ & $6.79 \pm 0.34$ & $6.72 \pm 0.32$ & $6.75 \pm 0.35$ \\
\hline & Ammonia, mg / 1 & $139 \pm 7.3$ & $142 \pm 7.9$ & $143 \pm 72$ \\
\hline \multirow{3}{*}{$\begin{array}{l}\text { Volatile fatty } \\
\text { acid, mol / } 1\end{array}$} & Acetic acid & $48.7 \pm 2.4$ & $47.5 \pm 2.4$ & $49.1 \pm 2.6$ \\
\hline & Propionic acid & $19.8 \pm 0.9$ & $20.1 \pm 1.0$ & $19.2 \pm 0.8$ \\
\hline & Butyric acid & $18.2 \pm 0.9$ & $18.7 \pm 0.8$ & $17.9 \pm 0.1$ \\
\hline \multicolumn{2}{|c|}{ Total microbial count, CFU / ml } & $6.48 \times 10^{8} \pm 0.31$ & $6.38 \times 10^{8} \pm 0.32$ & $6.52 \times 10^{8} \pm 0.34$ \\
\hline \multicolumn{2}{|c|}{ Cellulolytic bacteria, CFU / ml } & $5.52 \times 10^{6} \pm 0.28$ & $5.49 \times 10^{6} \pm 0.25$ & $5.47 \times 10^{6} \pm 0.27$ \\
\hline \multicolumn{2}{|c|}{ The number of ciliates, thousand / $\mathrm{ml}$} & $795.4 \pm 35.3$ & $801.3 \pm 39.5$ & $789.6 \pm 40.2$ \\
\hline \multicolumn{2}{|c|}{ Movement of ciliates, score } & $4.5 \pm 0.1$ & $4.4 \pm 0.1$ & $4.3 \pm 0.1$ \\
\hline \multicolumn{2}{|c|}{ The activity of cicatricial microflora, min. } & $4.5 \pm 0.1$ & $4.4 \pm 0.1$ & $4.4 \pm 0.1$ \\
\hline \multirow[t]{2}{*}{ Activity } & Amylolytic activity. $\mathrm{mg} / \mathrm{ml}$ & $41.8 \pm 2.2$ & $39.7 \pm 1.9$ & $40.5 \pm 2.1$ \\
\hline & Cellulolytic activity. $\%$ & $6.2 \pm 0.2$ & $6.1 \pm 0.3$ & $5.9 \pm 0.3$ \\
\hline & & \multicolumn{3}{|c|}{ After 4 months of experiment } \\
\hline & Acidity, $\mathrm{pH}$ & $6.78 \pm 0.34$ & $6.82 \pm 0.42$ & $6.91 \pm 0.38$ \\
\hline & Ammonia, mg / 1 & $141.5 \pm 7.1$ & $147.8 \pm 7.4$ & $152.7 \pm 7.9$ \\
\hline \multirow{3}{*}{$\begin{array}{l}\text { Volatile fatty } \\
\text { acid, mol / } 1\end{array}$} & Acetic acid & $51.2 \pm 2.2$ & $54.9 \pm 2.3$ & $57.1 \pm 2.1$ \\
\hline & Propionic acid & $21.4 \pm 0.6$ & $23.4 \pm 0.7$ & $24.1 \pm 0.9$ \\
\hline & Butyric acid & $18.3 \pm 0.8$ & $16.9 \pm 0.9$ & $16.4 \pm 0.8$ \\
\hline \multicolumn{2}{|c|}{ Total microbial count, $\mathrm{CFU} / \mathrm{ml}$} & $7.18 \times 10^{8} \pm 0.35$ & $7.92 \times 10^{8} \pm 0.38$ & $8.35 \times 10^{8} \pm 0.42 *$ \\
\hline \multicolumn{2}{|c|}{ Cellulolytic bacteria, CFU / ml } & $5.87 \times 10^{6} \pm 0.28$ & $6.40 \times 10^{6} \pm 0.32$ & $6.71 \times 10^{6} \pm 0.34$ \\
\hline \multicolumn{2}{|c|}{ The number of ciliates, thousand / $\mathrm{ml}$} & $985.2 \pm 43.4$ & $\begin{array}{c}1058.1 \pm \\
50.8 \\
\end{array}$ & $\begin{array}{c}1112.3 \pm \\
51.4^{*} \\
\end{array}$ \\
\hline \multicolumn{2}{|c|}{ Movement of ciliates, score } & $4.3 \pm 0.1$ & $4.5 \pm 0.1$ & $4.8 \pm 0.1$ \\
\hline \multicolumn{2}{|c|}{ The activity of cicatricial microflora, min. } & $4.3 \pm 0.1$ & $4.2 \pm 0.1$ & $4.1 \pm 0.1$ \\
\hline \multirow[t]{2}{*}{ Activity } & Amylolytic activity. $\mathrm{mg} / \mathrm{ml}$ & $42.3 \pm 1.3$ & $44.8 \pm 1.4$ & $47.1 \pm 1.5$ \\
\hline & Cellulolytic activity. $\%$ & $6.8 \pm 0.3$ & $7.1 \pm 0.3$ & $7.4 \pm 0.4$ \\
\hline
\end{tabular}

$* \mathrm{P} \leq 0,0$

\section{Conclusion}

Summarizing the data obtained during the study, we can conclude that the preliminary germination of rapeseed in a $0.05 \%$ nicotinic acid solution with its subsequent extrusion, helped to improve cicatricial digestion in calves and dairy cows in the third experimental group, which shows the comparison indicators of the third group with the control group (first group) and the group for which extruded grain is used for feeding (second group).

One of the factors contributing to the improvement of cicatricial digestion is the use of a $0.05 \%$ nicotinic acid solution during the germination of rape, which, according to R.S. Grewal et al., [15] promotes the digestibility of animal feed nutrients

Another factor is the preliminary germination of rapeseed. So, according to the results of scientific research, L.I. Butenko and L.V. Ligai found that germination of seeds of cereal crops increases the number of essential amino acids, trace elements, vitamins $\mathrm{E}$ and group $\mathrm{B}$, as well as increases the eatability of the feed and the digestibility of its nutrients [16]. Germination of grain leads to the activation of their enzymes of the grain, breaking down complex nutrients into pure compounds that are easily absorbed by the animal body.
The next factor contributing to the improvement of cicatricial digestion is extrusion, in which for 5-7 seconds (time spent in the extruder), temperature $\left(120-180^{\circ} \mathrm{C}\right)$, and pressure $(25-50 \mathrm{~atm})$ Act on the grain feed. Due to this, the extruded feed becomes disinfected, the complex nutrients of the feed are broken down into pure compounds, which is confirmed by the data in the descriptions of the experimental activity [17-20].

Thus, due to germination and subsequent extrusion, starch and crude fiber are broken down to di- and monosaccharides, and proteins to amino acids, which, ultimately, improves the scar content and is expressed in an increase in the amount of acetic and propionic acids and a decrease in butyric acid, and also in improving microorganisms of microflora and increasing their activity in cicatricial content.

\section{References}

1. S.J. Cho, K.M. Cho, E.C. Shin, W.J. Lim, S.Y. Hong, B.R. Choi, et.al., J. Microbial. Biotechnol., 16, 92-101 (2006)

2. S. Sadet-Bourgeteau, C. Martin, D. Morgavi, Vet. Microbiol., 146, 98-104 (2010) 
3. Y. Chen, G.B. Penner, M. Li, M. Oba, L.L. Guan, Appl Environ Microbiol., 77, 5770-5781 (2011)

4. G. Sayers, P.X. Marques, N.J. Evans, L. O’Grady, M.L. Doherty, S.D. Carter, J.E. Nally, J. Clin. Microbiol., 47, 1199-1201 (2009)

5. S. Mao, W. Huo, W. Zhu, Curr. Microbiol., 341350 (2013a)

6. S.E. Power, P.W. O'Toole, C. Stanton, R.P. Ross, G.F. Br. J. Nutr, 111, 387-402 (2014)

7. M. Kim, M. Morrison, Z. Yu, FEMS Microbiol. Ecol., 76, 49-63 (2011)

8. J.C. McCann, T.A. Wickersham, J.J. Loor, Bioinfor. Biol. Insights, 8, 109 (2014)

9. M. Li, M. Zhou, E. Adamowicz, J.A. Basarab, L.L. Guan, Vet. Microbiol., 155, 72-80 (2012)

10. Ismail Mahmoud Ali Shahhat, Gamal Mahmoud Ghazal, Ghada Samir Mohamed, Int. J. of Pharmacognosy and Phytochemical Res. 15, 6(4), 866-873 (2014)

11. I.P. Kondrahin, A.V. Arhipov, V.I. Levchenko, G.A. Talanov, L.A. Frolova, V.E. Novikov (KolosS, Moscow, 2004)
12. R.K. Konka, D.S. Kumar, J.V. Ramana, A. Ravi, E.R. Rao, Anim. Nutr. Feed Technol., 16(1), 171-179 (2016)

13. P.C. Lailer, S.S. Dahiya, T.R. Chauhan, Indian. J. Anim. Sci., 75(1), 84-91 (2005)

14. V.G. Sofronov, A.S. Sajfullin, E.I. Yamaev, N.I. Danilova, SH.K. SHakirov, P.V. Sofronov, E.L. Kuznecova, Transactions of Kazan State Academy of veterinary medicine named after N.E. Bauman, 232, 133-136 (2017)

15. R.S. Grewal, M. Wadhwa, M.P.S. Bakshi, Indian J. Anim. Nutr., 29, 9-14 (2012)

16. L.I. Butenko, L.V. Ligaj, Fundamental research, 4-5, 1128-1133 (2013)

17. R. Alonso, E. Orue, M.J. Zabalza, G. Grant, F. Marzo, J. of the Sci. of Food \& Agricult., 80(3), 397-403 (2000)

18. R. Alonso, A. Aguirre, F. Marzo, Food Chem., 68, 159-165 (2000)

19. B. Laurence, T. Pablo, R. Jacques, Y. Chilliarda, Animal Feed Sci. and Technol., 222, 31-42 (2016)

20. N. Ciganas, R. Gružauskas, R. Stankevičius, G. Dovidaitienè, I. Kudlinskienè, Vet. Med. Zoot., 73(95), Supplement, 19-23 (2016) 